\title{
Una breve historia política de México a través del Archivo Thomas S. Hunter (1913-1938)
}

\author{
Juan González Morfin*
}

\section{INTRODUCCIÓN}

Supe de la existencia del Archivo Thomas S. Hunter de la Universidad Panamericana posiblemente en octubre de 2015. Por diversas razones —una de ellas porque había oído que estaba conformado sobre todo por recortes de periódico - no fue sino hasta febrero de 2019 que me decidí a conocerlo: muchas cajas de libros y revistas con un catálogo que permite saber cuál es el contenido de cada una y, sobre todo, veinticinco cajas con decenas de legajos catalogados por temas, la mayoría de ellas con el título en inglés, con abundante material hemerográfico — recortes de diarios y revistaspacientemente clasificados y, en su mayoría, foliados muy probablemente por quien los coleccionó: Thomas S. Hunter. ${ }^{1}$

De una primera inmersión en el catálogo del archivo Hunter, la impresión que se puede sacar sobre su recopilador es que se trató de un católico culto, que hablaba al menos tres idiomas: español, francés e inglés, y que estaba preocupado especialmente por dos temas: por un lado, la tirante situación que se vivió entre la Iglesia católica y el Estado en México durante los gobiernos emanados de la Revolución y, por otro, la relación bilateral México-Estados

* Universidad Panamericana, Ciudad de México, México. Correo electrónico: jgonzalezmorfin@yahoo.com.mx. ORCID: https://orcid.org/0000-0002-7278-7872

1 Thomas S. Hunter (1894-1970): nació en Warren, Pennsylvania, era nieto del famoso ingeniero ferroviario Thomas W. Seabrook. Participó en la Primera Guerra Mundial y, al terminar, comenzó a trabajar en la industria de la minería. Llegó a México en 1920 contratado por la American Smelting Company. Ese mismo año se casó con la mexicana Juanita Gómez Camacho. En 1924 comenzó a trabajar en la industria del tabaco, en la cual permaneció hasta su jubilación en la cigarrera La Moderna, de la que fue gerente de publicidad. En los años treinta colaboró en la recolección de fondos para las actividades de la Liga Nacional Defensora de la Libertad. Escribió algunas obras sobre publicidad y artículos históricos. Fue consejero del ITESM en los años cincuenta. Perteneció a la Academia de Ciencias Históricas de Monterrey. 
Unidos, sobre todo en sus nexos comerciales. También encontramos material abundante sobre el avance del comunismo a nivel internacional y dentro del territorio mexicano; sobre la situación de España antes, en y después de la Guerra Civil; y sobre temas de publicidad y mercadotecnia.

En relación con la complicada relación de la Iglesia católica y el Estado durante los años 1925 a 1940, se debe decir que es el tema más documentado con hasta cuatro legajos de abundante documentación en algunos años, como 1926. Sin embargo, a partir del gobierno de Manuel Ávila Camacho, decae por completo el interés sobre este asunto, probablemente porque la situación se tornó cada vez menos tensa.

En este trabajo se buscará aprovechar parte de ese material recopilado por Hunter para dar una visión histórica de México a través de la prensa sobre los ejes que fueron atractivos para el compilador. Su percepción de la historia estará presente en todo momento, pues fue él quien se encargó de recabar los datos que ahora sistematizamos, aunque no su opinión, pues en el archivo no se halla una sola nota personal ni escrito alguno de Hunter. El método que seguiremos será "dejar hablar a la prensa", más que hacer una crítica de lo reportado, pues serán precisamente las crónicas, noticias y artículos recopilados en este archivo los que nos guíen para adentrarnos en la historia contemporánea de nuestro país. Todo esto con el objetivo doble de dar a conocer el Archivo Hunter y de abrir posibles líneas de investigación histórica. Por esto último, se evitará en lo posible retomar los tópicos más tratados por la historiografía, y se buscará únicamente aportar nuevas luces en aspectos menos atendidos sin pretender hacer un repaso de todo lo ocurrido en estos años.

\section{Lane Wilson y SU RESPONSABILIDAD EN la CaÍda de Madero}

La recopilación de recortes sobre el presidente Madero que se encuentran en el archivo Hunter corresponde a los años 1926 y 1934 y a dos problemáticas concretas: la participación del embajador norteamericano Henry Lane Wilson en la caída del régimen maderista y una controversia surgida entre el escritor Alfonso Junco - por atacar a Carranza y señalarlo incluso como traidor a Madero- y un carrancista convencido, el coronel Bernardino Mena Brito.

A 13 años de la tragedia de Madero, diversos diarios retomaron el tema de su muerte e, incluso, el ex embajador estadounidense Henry Lane Wilson realizó interesantes declaraciones al respecto.

El 25 de febrero de 1926, el licenciado Luis Manuel Rojas, diputado de la legislatura vigente en los días de la Decena Trágica y amigo personal de Madero, hizo declaraciones al periódico Excélsior con el fin de puntualizar algunos hechos en torno a la muerte del prócer. En éstas afirmó: “Todo el mundo sabe o recuerda que los principales hombres de quienes dependió la 
muerte de Madero fueron: $1^{\mathrm{o}}$-General Victoriano Huerta, $2^{\circ}$-Henry Lane Wilson, $3^{\circ}$-General Félix Díaz, $4^{\circ}$ General Mondragón y $5^{\circ}$ Licenciado don Rodolfo Reyes". ${ }^{2}$

Las acusaciones contra Lane Wilson, quien todavía estaba vivo y viviendo el ostracismo al que había sido tácitamente condenado por su actuación en México, eran tan contundentes o más que las que había hecho Rojas siendo diputado en los días que siguieron a la tragedia: ${ }^{3}$ "En cuanto a la responsabilidad de Henry Lane Wilson, siempre la he considerado yo al nivel de la del general Huerta, puesto que este usurpador no se hubiera atrevido a ordenar el asesinato del señor Madero, si no hubiera contado con la complicidad expresa o tácita del embajador de los Estados Unidos, que tenía en sus manos el destino de México". ${ }^{4}$

En esa misma edición, el diario hacía pública una carta facilitada por Rojas en la que Manuel Bonilla, funcionario de Madero, contaba un hecho inédito y casi inverosímil que apuntaba a ser la causa de la malquerencia de Lane Wilson hacia el presidente:

El señor Presidente Madero me refirió que la señora de Wilson había insinuado a la señora de Madero que el Embajador no ganaba lo suficiente para sus necesidades y que desearía que tuviera algún negocio en que ganar siquiera cincuenta mil pesos anuales. No recuerdo que haya llegado al extremo de solicitar abiertamente el auxilio, si bien la conversación no podía tener otro objeto.

Don Ernesto, ${ }^{5}$ al enterarse le dijo al Presidente que sería bueno que le dieran cuatro mil pesos mensuales a Lane Wilson, y que D. Porfirio le pasaba esa mensualidad...

El señor Madero, no recuerdo si por mi insinuación o sin necesidad de ella, se negó a darle a Wilson lo que aconsejaba don Ernesto. ${ }^{6}$

Como a este artículo se sumaron otros en la línea de responsabilizar a Lane Wilson de la tragedia de 1913, éste se vio en la necesidad de dar su versión de los hechos, la cual fue publicada in extenso por el periódico Excélsior. Algunas de las afirmaciones que hace tropiezan con muchos testimonios en su contra; sin embargo, es conveniente contar también con el punto de vista del acusado:

2 Excélsior, 25 de febrero de 1926, Archivo Hunter (AH), caja 27, legajo Madero, s.n.f.

3 El 23 de febrero de 1913, el diputado Luis Manuel Rojas hizo unas declaraciones en las que acusaba al embajador Lane Wilson de ser el asesino moral de Madero y Pino Suárez, así como de haber tenido conocimiento oportuno del golpe de Estado e, incluso, haber recibido en la embajada a los conspiradores.

4 Excélsior, 25 de febrero de 1926, AH, caja 27, legajo Madero, s.n.f.

5 Ernesto Madero, tío del presidente y secretario de Hacienda tanto con Madero como con su antecesor, Francisco León de la Barra.

6 Excélsior, 25 de febrero de 1926. Recorte de periódico en AH, caja 27, legajo Madero, s.n.f. 
He notado con profunda pena que en los últimos tiempos ha vuelto a hablarse en México de la leyenda que relacionó a la Embajada norteamericana con el derrocamiento del Presidente don Francisco I. Madero. Hace once años que se inventó esta historia y que fue comunicada al mundo por un corresponsal norteamericano desde la ciudad de México. ${ }^{7}$ Como en los cargos formulados se mezclaban mi buen nombre y el del Gobierno americano, promoví inmediatamente un juicio por difamación ante un tribunal competente, contra el director del magazine que publicó el artículo y obtuve un fallo favorable. ${ }^{8}$

Continúa su apología proporcionando una serie de datos que la historiografía ha presentado de manera diferente, por ejemplo, niega haber conocido a Victoriano Huerta antes de la Decena Trágica. Asegura que no cruzó con él "mensajes, ni verbales ni escritos, salvo los que (...) se referían a la impartición de garantías a los extranjeros residentes en la ciudad de México, y fueron redactados en la inteligencia de que Huerta era leal al Presidente Madero". ${ }^{9}$ Declara que lo que ha dicho sobre Huerta, "se aplica igualmente al general Félix Díaz, a quien ni conocía, ni había visto antes de la decena trágica, y con quien tan sólo crucé los mensajes de que di cuenta al Departamento de Estado en Washington". ${ }^{10}$

Argumenta que usó toda su fuerza como embajador para que, una vez que se había consumado el cuartelazo, Huerta "tomase precauciones para garantizar la vida de los señores Madero y Pino Suárez, y que pusiese en libertad a todos los ministros de Madero que estuviesen detenidos". ${ }^{11}$ Menciona haber hecho "renovadas gestiones para salvar las vidas de Madero y Pino Suárez" y narra minuciosamente una de éstas:

Tras una de nuestras visitas, regresamos a la Embajada y encontramos ahí a la señora Madero. Parecía abrigar temores por las intenciones del nuevo Gobierno hacia su esposo, y nos dijo por añadidura que aquél padecía a causa de la prisión y de los malos alimentos. Nos pidió que fuésemos a ver nuevamente a Huerta y

7 De hecho Lane Wilson ignora, o finge ignorar, el informe que en 1913 fue presentado al presidente Woodrow Wilson por un agente especial comisionado para indagar en México sobre las imputaciones que se le hicieron al embajador desde los mismos días de la tragedia, y no dos años después, como pretende hacer creer. Nos referimos al informe del diplomático norteamericano William Bayard Hale, realizado entre abril y junio de 1913, y que corrobora todas las imputaciones en su contra (Harrison, "Henry Lane Wilson, el trágico de la Decena", pp. 379-402).

$8 \quad$ Henry Lane Wilson, "El Embajador H. L. Wilson ha roto al fin su silencio. Refiere cuál fue su actuación durante la Decena Trágica”, Excélsior, 15 de julio de 1926, AH, caja 27, legajo Madero, s.n.f.

$9 \quad$ Ibid.

10 Ibid.

$11 \quad$ Ibíd. 
que le dijésemos que el señor Madero abandonaría a México para siempre si se le salvaba la vida. En consecuencia, volvimos a ver a Huerta y celebramos una conversación directa con él sobre el particular. Durante la entrevista manifestó el general Huerta que no sabía qué hacer con Madero; que había hecho preparar un tren para que lo condujera junto con su familia fuera del país, pero que, cuando el tren esperaba en la estación, se interceptaron los telegramas del comandante militar de Orizaba, en que éste asentía a levantarse contra el Gobierno y a apoderarse del señor Madero cuando el tren pasara por aquel lugar. Agregó que había pensado en internar a Madero en un manicomio, o en hacerlo juzgar por el Congreso por violaciones a la Constitución. Nos preguntó nuestra opinión sobre estos proyectos. Contestéle, con la aprobación de von Hintze, ${ }^{12}$ que no teníamos autorización para hablar en ese caso; que él tenía que hacer lo que fuese más provechoso para México. Agregué todavía extraoficialmente que si estuviera en su lugar, pondría a ambos prisioneros en absoluta libertad. Huerta contestó: "Serían asesinados en el término de una hora, pues hay muchos que desean su muerte". Le recomendé nuevamente entonces que trasladase a los prisioneros a un lugar cómodo y seguro (había yo comunicado a Washington que estaban siendo tratados en forma abominable) y me replicó: "Cumpliré vuestros deseos, ya que estos hombres no están seguros aquí”. Con esto terminó la entrevista. ${ }^{13}$

Termina su exculpación del asesinato de Madero con esta reflexión: "Ni yo, ni el Ministro alemán von Hintze, abrigamos la menor duda respecto de la intención de Huerta de proteger la vida de Madero. Era evidente que le convenía conservar el respeto del mundo y no manchar el nuevo Gobierno con un crimen que repugnaría a la humanidad civilizada". ${ }^{14}$

Pasa después a describir y a defender su papel en el llamado "Pacto de la Embajada" que, a su juicio, trajo al menos "una paz temporal y, si el general Huerta hubiese cumplido religiosamente sus compromisos con Félix Díaz, de ellos se habría derivado, a mi juicio, una paz permanente". ${ }^{15}$

Concluye sus alegatos apologéticos afirmando que "no pueden presentarse pruebas en contrario, porque no las puede haber respecto a lo que no sucedió", por lo que solamente "el prejuicio o el interés político pueden formular asertos vagos; pero esta leyenda no tiene lugar en el dominio de la verdad". ${ }^{16}$

Como documento, es realmente valiosa la defensa que hace Wilson de su actuación en los acontecimientos que culminaron con el derrocamiento y

12 Paul von Hintze, ministro plenipotenciario de Alemania ante los gobiernos de Francisco León de la Barra y Madero y, posteriormente, de Huerta. Se retiró del país en 1914 para seguir prestando servicios diplomáticos primero en China y luego en Noruega. Entre julio y noviembre de 1918, fue ministro de relaciones exteriores de Alemania.

13 Ibíd.

$14 \quad$ Ibid.

15 Ibid.

16 Ibid. 
asesinato del presidente Madero. Muchas de sus aseveraciones sirven para contrastar algunas informaciones obtenidas por otras fuentes. ${ }^{17}$ Sin embargo, la acuciosa averiguación que sobre los hechos realizó el diplomático William Bayard Hale, y que sirvió al presidente estadounidense Woodrow Wilson para retirarlo como embajador en México, aporta datos diametralmente opuestos:

No hubo durante toda la "decena trágica" ni un momento en que no hubiera sido posible "poner término a la desolación", "poner punto final a este innecesario derramamiento de sangre", mediante una seria advertencia de la Embajada norteamericana a los oficiales traidores del ejército, en la cual se les hubiera dicho que los Estados Unidos no estaban dispuestos a patrocinar otros métodos que no fueran los constitucionales y pacíficos, y que no otorgaría su reconocimiento a ningún gobierno erigido por la fuerza. El presidente Madero no fue traicionado y arrestado por sus oficiales sino en el momento en que ya no hubo dudas de que el Embajador norteamericano no tenía objeción contra semejante hazaña. El plan para el establecimiento inmediato de una dictadura militar no pudo haberse elaborado nunca, excepto en la Embajada norteamericana, bajo el patrocinio del Embajador norteamericano y con su promesa, en nombre de su Gobierno, de un rápido reconocimiento. Madero nunca habría sido asesinado si el Embajador norteamericano hubiera dado a entender en forma clara que la conspiración debía detenerse antes de llegar al crimen. ${ }^{18}$

Como Luis Manuel Rojas había situado al licenciado Rodolfo Reyes a la misma altura que Lane Wilson en el asesinato de Madero, Reyes, quien había colaborado activamente en los sucesos de la Decena Trágica y formó parte del gobierno de Victoriano Huerta, desde España respondió asumiendo la responsabilidad de haber participado en el levantamiento y en el derrocamiento de Madero, mas no así en su asesinato, pues, afirmaba,

quienes nos honramos con pertenecer a la familia del General Reyes, siempre hemos reconocido, sin distingos, que murió en un acto militar, no guardando para nadie estériles odios; por lo que a mí respecta puedo decir que mi devoción por su memoria, que es culto, hubiera bastado a detenerme si mi temperamento, en un momento de locura, fuera capaz del crimen, ya que jamás mancillaría esa memoria echando un borrón sobre nuestro nombre. ${ }^{19}$

17 Manuel Márquez Sterling, diplomático cubano residente en México durante los días del asesinato de Madero, cuenta haber recIbído de la esposa de Madero una versión contraria a las afirmaciones de Lane Wilson (Márquez, Los últimos dias del Presidente Madero, pp. 544-547).

18 Harrison, "Henry Lane", p. 401.

19 Rodolfo Reyes, "El Lic. Rodolfo Reyes hace revelaciones relacionadas con la muerte de F. Madero", Excélsior, 8 de abril de 1926, AH, caja 27, legajo Madero, s.n.f. 
En cuanto a la ejecución de Madero y Pino Suárez, Reyes responsabiliza del todo a Huerta pues los victimados no estuvieron nunca a disposición de nadie que no fuera él: "Nosotros, como rebeldes de la Ciudadela, no tuvimos a nuestra disposición un segundo a los funcionarios derrocados y, al formarse gobierno, menos" ${ }^{20}$ Terminaba su defensa, sin embargo, reconociendo haberse equivocado, lo que no justificaba que se le imputara el crimen de Madero, pues, decía, "si erré en política, eso no me coloca en condiciones de paria sobre el que pueda echarse fango impunemente". ${ }^{21}$

\section{La Relación de Madero con los Católicos Y UN ATAQUE INÉDITO CONTRA CARRANZA}

En febrero de 1934 el columnista Alfonso Junco publicó en El Universal un artículo titulado "Madero, Huerta y los católicos". ${ }^{22}$ El texto, de carácter claramente apologético, expone la buena relación existente entre los católicos y el presidente Madero, que propició la fundación y desarrollo incipiente del Partido Católico Nacional. Narra después cómo "la atronadora popularidad del Madero insurgente fue mermándose mucho ante el Madero gobernante. Sin mengua de las rectas intenciones, había falta de coherencia, de vigor, de tacto, de lucidez". ${ }^{23}$

Las conjuras en contra del presidente estuvieron a la orden del día. Un miembro del Partido Católico, Juan Villela, dirigió una consulta al episcopado mexicano reunido en la ciudad michoacana de Zamora para la Gran Dieta de Círculos Católicos de Obreros. La respuesta fue "que por ningún motivo podrían los católicos, si se les solicitaba para ello, participar en conspiración alguna". ${ }^{24}$

La carta de los obispos consultados fue, si cabe, todavía más explícita y buscaba disuadir a cualquier católico que estuviera involucrado en conjuras y conspiraciones:

Como Prelados, así como hemos dejado plena libertad al Partido Católico para designar sus candidatos, promover su propaganda y usar de sus derechos políticos, no podemos de ninguna manera callar cuando se trata de los principios morales que deben ser respetados a todo trance.

\footnotetext{
$20 \quad$ Ibid.

$21 \quad$ Ibid.

22 Alfonso Junco, "Madero, Huerta y los católicos", El Universal, 10 de febrero de 1934, AH, caja 29, legajo Wilson-Huerta-Carranza (2), s.n.f.

23 Ibid.

24 Ibid.
} 
Entre esos principios está el que prohíbe y condena toda rebelión contra las autoridades constituidas; pues aunque hubo algunos autores católicos que creyeron lícita la rebelión en circunstancias excepcionales, después de las Encíclicas de León XIII no puede sostenerse tal teoría y todo católico debe reprobar cualquier rebelión.

Mil veces ganará nuestra Patria si logramos afianzar el principio de autoridad, que no con el cambio de gobierno siempre problemático, que fácilmente llega a la anarquía. ${ }^{25}$

Continuaba Junco narrando cómo con Huerta se dividió la opinión de los miembros del Partido Católico y, mientras algunos, "compelidos por las circunstancias", creyeron deber "cooperar para que el gobierno tomara una ruta sana y salvara al país de la anarquía amenazante", ${ }^{26}$ otros, como el presidente del partido, Gabriel Fernández Somellera, y el director del diario La Nación, Enrique Zepeda, fueron perseguidos por el régimen huertista e, incluso, llegaron a estar en la cárcel y, “en cuanto a la religión nacional, ni Madero la hostilizó, ni Huerta la hostiliza", ${ }^{27}$

El punto álgido del artículo vendría al tocar la figura de Carranza. A quien señala primero como "adicto a don Porfirio" y aliado de Madero únicamente por oportunismo, ya que, "esta alianza fortuita no era afinidad real". De hecho, al parecer de Junco, "Carranza se sentía superior a Madero y no ocultaba su desestimación y su desdén". ${ }^{28}$ La animadversión de Carranza hacia el presidente habría crecido cuando se le suspendió un subsidio federal para pagar unas fuerzas locales que como gobernador tenía a su disposición. A raíz de esto, incluso se hablaba de una conspiración carrancista contra Madero al lado del general Bernardo Reyes, la cual Junco conoció por un "importante colaborador de Carranza". En cualquier caso, Junco hacía constar que

don Venustiano Carranza y don Francisco [Madero] estaban en pésimas relaciones; que, ya en las postrimerías del régimen, el Gobernador había enviado al Presidente, por conducto personal, una comunicación de tal modo intemperante que Madero se la había mandado devolver por el mismo conducto diciéndole que no podía aceptar en su archivo papeles de esa calidad. ${ }^{29}$

25 “Carta a los directores del Partido Católico Nacional”, febrero 16 de 1913, Archivo Histórico de la Arquidiócesis de México (AHAM), fondo episcopal: José Mora y del Río, caja 88, expediente 17 .

26 Junco, "Madero, Huerta".

27 Ibid.

28 Ibid.

29 Ibid. 
El artículo, concluye categórico:

La animadversión es indudable, y no se advierte sino oportunismo en aparecer el Primer Jefe como vengador del Presidente derrocado. Ni puede hallarse pretexto y añagaza en querer cohonestar la persecución irreligiosa de entonces, achacando a los católicos un amor para Huerta y un odio para Madero que estuvieron muy lejos de profesar. ${ }^{30}$

Las afirmaciones del columnista cayeron muy mal entre algunos militares y funcionarios de lo que había sido el gobierno de Carranza. Uno de ellos fue el coronel Bernardino Mena Brito quien, además de alegar que las acusaciones contra el Primer Jefe eran infundadas, arremetió contra los católicos que Junco buscaba exonerar, pues

sabiendo la conspiración, los católicos no pusieron los medios para evitarla y, una vez consumada, siguieron a Huerta a pesar de haber subido por "sucio camino", es decir, sobre el cadáver de Madero... ¿Hubiera querido el señor Junco que la conducta del señor Carranza para con Madero hubiese sido la de los católicos, del silencio y la espera? La lealtad política exigida por el señor Junco al señor Carranza y cumplida por éste con su levantamiento contra Huerta, ¿no puede alcanzar por ningún motivo a los miembros del Partido Católico, que supieron con anticipación la revuelta contra Madero y participaron en el gobierno de Huerta? ${ }^{31}$

La confrontación de ideas y datos entre Alfonso Junco y Bernardino Mena Brito consiguió así traer a la memoria dos situaciones que, para esos años, tenían en realidad un mínimo de importancia: de un lado, la sospecha de que Carranza en algún momento hubiera estado involucrado en la revuelta de Reyes, pero que, una vez que no fue él quien triunfó, sino Díaz y Mondragón junto con el traidor Huerta, prefirió rebelarse contra el gobierno emanado del golpe de Estado, mientras que si hubiera llegado Reyes al poder se le hubiera unido y, por otra parte, revivió la acusación contra los católicos de haber apoyado el gobierno de Huerta, pues de hecho algunos sí lo hicieron, con lo que la finalidad de Junco de mostrarlos intachables resultó contraproducente.

\section{UnA DEFENSA A UltranZa DE HuerTa}

En varios de los artículos que recoge el archivo Hunter, una figura tan desacreditada de la historia de esta época, el general Victoriano Huerta, no

Ibid.

Bernardino Mena Brito, "Madero, Carranza y el Señor Junco", El Universal, 16 de abril de 1934, en AH, legajo Wilson-Huerta-Carranza (2), s.n.f. 
es impugnada como se podría esperar y, en más de uno, su papel es incluso sobrevalorado. Es el caso de uno publicado en el periódico de Los Angeles, Pro Patria, al parecer editado por simpatizantes y ex colaboradores del régimen huertista que se hallaban exiliados en los Estados Unidos. El artículo es muy extenso, abarca una plana completa del diario y se encuentra lleno de alabanzas a Huerta, a quien se le ubica como una víctima de los Estados Unidos y, más aún, de las diferentes organizaciones masónicas.

Huerta — según el artículo de Pro Patria - constituyó un gobierno firme y se granjeó la confianza del público. Abrió el Congreso en Nombre de Dios, y dijo que había de rogar para que Dios enviase la paz al país y así la Ley de Dios rigiese en México. Esto era cosa nueva, porque ningún presidente antes que él sintió la necesidad de Dios, ni menos se atrevió a invocarla. El pueblo aplaudió, pero muchos miembros del Congreso expresaron su disgusto por ello. ${ }^{32}$

Continúa el relato con una serie de hechos poco verosímiles: una comisión de masones mexicanos y americanos le propuso a Huerta "que entrara en la masonería y prometiéndole... que si lo hacía así y seguía los principios masónicos, ellos le elegirían presidente y le conseguirían el ser reconocido como tal por los Estados Unidos". ${ }^{33}$ La negativa de Huerta no se hizo esperar "fue terminante y el modo de darla fue muy característico suyo. Enseñando un escapulario dijo que era su distintivo, y aunque él no había sido tan buen católico como debía, no podía sustituirlo por un emblema masónico, y que deseaba vivir y morir como católico". ${ }^{34}$

Siempre en la lógica del artículo, las represalias masónicas no se hicieron esperar y los enemigos de Huerta comenzaron a recibir apoyo de los Estados Unidos: Carranza pudo importar armas, Obregón recibió de la American Federation of Labor 5000 rifles y 5000000 de cartuchos, "Villa, Ángeles y sus amigos fueron abastecidos de armas y dinero por ciertos capitalistas americanos..." 35 y, de esa forma, "se consiguió la caída de Huerta y el triunfo de los carrancistas, cuya obra revolucionaria y antipatriótica continúa todavía" ${ }^{36}$

\section{Los Agentes CONFIDENCIALES EN la ÉPoca de CARRANZa}

Un asunto de particular interés para Hunter, según se aprecia por los diversos recortes de periódico, fue la participación de agentes confidenciales

32 "El Presidente Huerta y la Masonería", Pro Patria, 31 de enero de 1936, en AH, caja 29, legajo Wilson-Huerta-Carranza (2), s.n.f.

33 Ibíd.

34 Ibid.

35 Ibid.

36 Ibid. 
del gobierno norteamericano en la época preconstitucional y durante el gobierno de Carranza. Estos personajes actuaban a modo de diplomáticos sin representación oficial, pero con la seguridad para sus interlocutores que tenían un cauce de entendimiento directo con el gobierno norteamericano. Fue un modo, podríamos llamar, abusivo de mantener relaciones diplomáticas al mismo tiempo con las diferentes facciones en conflicto.

Cabe recordar que, por la naturaleza del conflicto, afloraron diversos gobiernos que al mismo tiempo pretendían ser cada uno de ellos el legítimo. Debido a esto, hubo una época en la que ni los Estados Unidos ni las demás naciones con intereses en México podían tener relaciones diplomáticas ciertas con alguna de las distintas facciones, por lo que los consulados y embajadas pasaron a convertirse sólo en agencias de los diferentes países y, por ello, quienes anteriormente fungían como cónsules, embajadores o ministros de tales misiones diplomáticas, permanecieron en el mejor de los casos como "agentes confidenciales". ${ }^{37}$ Algo parecido fue necesario para las facciones revolucionarias en pugna, pues cada una de éstas, a falta de relaciones diplomáticas, tuvo que establecer principalmente con Estados Unidos sus propios agentes confidenciales, que operaban sobre todo a nivel de cabildeo con las diferentes instancias gubernamentales: secretarías de Estado, cámara de diputados, cámara de senadores, así como con la prensa. ${ }^{38}$

De entre los artículos seleccionados por Hunter para su archivo, hemos elegido resumir y comentar solamente dos de ellos: el primero, de Jorge Flores D., es casi una reseña de un libro publicado en 1929: Executive Agents in American Foreign Relations; ${ }^{39}$ el otro, una extensa crítica de Victoriano Salado Álvarez con comentarios anticarrancistas y resabios de un nacionalismo decimonónico.

A 25 años de su aparición, el libro de Wrinston reseñado por Jorge Flores D. ${ }^{40}$ sigue resultando interesante porque presenta un análisis desapasionado de lo que fueron los agentes confidenciales, una especie de balance histórico. Éstos, a la vista de Wriston, surgieron de la necesidad ética de Wilson de hacer valer la justicia en México ante la ilegalidad de Huerta, primero, y la anarquía que se vino a su caída, después.

Y como las palabras del Presidente Wilson no entrañaban un mero alarde de oratoria académica, sino que eran la expresión de un programa político que quería poner en obra para la realización de los principios arriba enunciados,

37 Véase Ulloa, La Revolución escindida, pp. 39-40, 117-118.

38 Véase Smith, "Diplomacia entre las sombras", pp. 1-16.

39 Henry M. Wriston, Executive Agents in American Foreign Relations, Baltimore, Johns Hopkins Press, 1929.

40 Jorge Flores D., "Los agentes confidenciales de Woodrow Wilson", Excélsior, 25 de enero de 1954, AH, caja 29, legajo Presidentes de México, s.n.f. 
ejerciendo para ello su influencia de todo género, de ahí la necesidad de un mecanismo que facilitase el propósito del antiguo profesor de Princeton, pues su consecución, como luego quedó a la vista, no era tarea fácil dentro de los conductos diplomáticos ordinarios. ${ }^{41}$

Mucho se ha escrito en torno a esta época preconstitucional, en la que llegaron a concurrir jefes del ejecutivo en un mismo momento. Sin embargo, el artículo no se decanta por describir la situación que se vivía, la da por conocida, y por ello remarca: "Se hizo indispensable recurrir entonces al empleo de agentes personales que solo mantuvieran constantemente informado al Presidente de los sucesos que ocurrían al sur del río Bravo, sino también para que, en ciertas circunstancias, le dieran su opinión y sus consejos, muy útiles para que él pudiera llegar a decisiones definitivas". ${ }^{42}$

En tanto que las facciones en pugna no prevalecieran sobre las otras y pudieran reclamar el reconocimiento pleno de su gobierno, tenían que acostumbrarse a interactuar con estos personajes cuya presencia, aclara el artículo, "no pasó inadvertida; se volvió pública y frecuente entre 1913 y 1916". ${ }^{43}$ Sus nombres: Carothers, Cánova, Silliman, Fuller, West, y un largo etcétera; sin embargo

la primacía corresponde al honorable John Lind, ex gobernador de Minnessota, a quien el Presidente Wilson designó en agosto de 1913 como su representante y vocero personal en la ciudad de México, después del retiro del embajador Lane Wilson (...). Tan vulgar se hizo entonces el nombre de Mr. Lind, que si mal no recordamos, sirvió de epígrafe a una revista editada por un grupo de humoristas y artistas de la caricatura. ${ }^{44}$

Otro agente destacado fue John P. Silliman, avecindado en el estado de Coahuila donde antes del inicio de la Revolución tenía boyantes negocios en el terreno de la ganadería y de la lechería, al tiempo que ejercía como pastor de una iglesia evangélica. Cónsul en Saltillo en 1907, prisionero de Huerta en 1914, al recuperar la libertad regresó a Estados Unidos donde se entrevistó con Wilson, de quien había sido compañero en Princeton y recibió

de él instrucciones, el 16 de julio de 1914, para que acompañara a Carranza en calidad de informador y observador (...). Tenía la misión de informar diariamente del desarrollo de los acontecimientos revolucionarios, que se sucedían con rapidez vertiginosa. Se unió al Primer Jefe del Ejército Constitucionalista en Monterrey, 
y siguió a su lado hasta la entrada triunfal a la ciudad de México. Cuando sobrevino la ruptura con la facción villista, Silliman viajó en tren especial hasta Washington, con la esperanza de que su presencia e informes de viva voz fueran útiles tanto a México como a los Estados Unidos. Inmediatamente regresó a la República, continuando en su labor confidencial hasta mediados del año $1916 .{ }^{45}$

Flores da algunos otros nombres y misiones concretas que desempeñaron, pero lo expuesto anteriormente puede servir para encuadrar mejor el artículo de Salado Álvarez que a continuación se reporta.

Es un estudio escrito casi 30 años antes, en 1925, esto es, con una visión más cercana en el tiempo de lo que se pretende describir. Desde el inicio busca desacreditar la actuación de Woodrow Wilson en relación con las diferentes facciones revolucionarias, lo cual es explicable porque Salado Álvarez procede de los intelectuales que estuvieron del lado de Huerta, incluso él mismo se sitúa en su escrito del lado de los reaccionarios.

Aunque en un primer momento menciona que la intención de su artículo es demostrar cómo Wilson terminó muy mal a los ojos de todos los mexicanos, sean libertarios o reaccionarios, rápidamente se olvida de su propósito inicial para hacer una descripción mordaz e irónica de un buen número de agentes confidenciales. De Lind se burla por su desconocimiento de México; de Silliman, por su timidez, servilismo y temor de perder su cargo, así como de su mal tino en el terreno diplomático, para lo que refiere la siguiente anécdota:

Silliman causó al cónsul alemán un verdadero chasco diciéndole con arrogancia "Ya tomamos Zacatecas, ya nos posesionamos de Torreón, ya vencimos a Villa", lo cual dio al inocente teutón la idea de que los Estados Unidos estaban aquí ya, en uso del famosos destino manifiesto, ocupando plazas del interior de la República; cuando lo único que el wilsoniano quería decir era que él estaba identificado con el carrancismo. ${ }^{46}$

Con el mismo tono despectivo continúa hablando de cada uno de los diferentes agentes confidenciales, lo que permite conocer una opinión que podría tener sus puntos de apoyo en la realidad sobre la figura de cada uno de éstos. Un ejemplo más, el representante de Wilson ante Villa, George C. Carothers, para Salado Álvarez fue "un individuo insignificante que se retiró a su tierra con un rico botín hecho al lado del Napoleón Bandido. Y en honor de la verdad y para no diferenciar a esos diplomáticos de mohatra, hay que decir con absoluta imparcialidad que ninguno descuidó llevar el agua a su molino mediante las trazas más inverecundas y rastreras". ${ }^{47}$

$45 \quad$ Ibid.

46 Victoriano Salado Álvarez, "Los agentes confidenciales de Wilson", Excélsior, 17 de octubre de 1925, pp. 5 y 8, AH, caja 29, legajo Wilson, Huerta, Carranza (1), f. 9.

47 Ibid. 
Del único que Salado vierte una buena opinión es de Duval West: "Un enviado hubo que sí cumplió con su deber, entre los muchísimos que omito y los que menciono; fue Duval West, de San Antonio, Tex., quien reveló al Gobierno americano lo que pasaba en México: quedó destituido sin tardanza". ${ }^{48}$

Y ya casi para finalizar su escrito, Salado expresa una sentencia lapidaria, como una especie de calificativo global a la tarea desempeñada por los diferentes agentes:

Esa diplomacia que se hacía a espaldas o con el consentimiento del Departamento de Estado, hizo más daño a los Estado Unidos que cien batallas perdidas. Esa diplomacia triple y cuádruple que rige desde los tiempos de Fernando VII y de Luis XV, con el nombre de "Diplomacia Secreta", "Diplomacia Doble" y "Secret du Roy", ha pasado a la historia anatematizada por sus pésimos resultados. El Ministerio de Relaciones nulificado y el triunfo de las camarillas son siempre de pésimo augurio y nadie debe emplearlo. ${ }^{49}$

Y sobre la actuación de Wilson en relación con México, no se ahorra un juicio igualmente radical: "Esa contradicción [la de haber usado la diplomacia secreta] tuvo en contra nuestra el hombre que fue un tejido de contradicciones, y por eso los que le habían llamado el Presidente de la Justicia, el Presidente vengador de Madero y otros motes llenos de baja adulación, abandonaron hace tiempo sus primitivas posiciones". ${ }^{50}$

\section{Carranza y su Relación con El PRESIDENTE Wilson}

No hace falta recordar que durante la época de Carranza, desde el desconocimiento de Huerta, muchas de sus acciones estuvieron entremezcladas con los intereses norteamericanos y la actitud tomada por este gobierno. Así lo muestran los recortes de periódico que rememoran esta época. La primera acción de Carranza, subraya Fabela, después de desconocer el gobierno del general Huerta, a quien consideraba traidor de las instituciones y usurpador del poder ejecutivo, fue "dirigirse por telégrafo al Presidente de los Estados Unidos, Mr. Taft, diciéndole que en sus carácter de gobernador de Coahuila y de acuerdo con los principios de la Constitución Federal de la República, había desconocido al usurpador, poniéndose al frente del movimiento que restauraría el orden constitucional". ${ }^{51}$ Este mensaje no obtuvo respuesta, quizá porque Taft

$48 \quad$ Ibid.

49 Ibid.

$50 \quad$ Ibid.

51 Isidro Fabela, "Política Internacional de Carranza. Primeros incidentes — 1913", Excélsior, 7 de abril de 1953, AH, caja 29 legajo Presidentes de México, s.n.f. 
estaba ya a un mes escaso de ser relevado por Woodrow Wilson. Aun con este menosprecio de lo que hacía, Carranza no tuvo empacho en volverse a dirigir a Taft para reclamarle la prisa con la que el gobierno de Taft había reconocido a un "gobierno espurio que ha acarreado la guerra civil al Estado de Coahuila que represento y que muy pronto se extenderá a todo el país (...). Espero que vuestro sucesor obrará con más circunspección acerca de los intereses sociales y políticos de mi patria". ${ }^{52}$

La actitud de Carranza hacia los Estados Unidos fue de constante reclamo por sus injerencias en la vida interna de México. Dos incidentes, entre otros muchos, confirman su repulsión a aceptar todo tipo de intromisiones. El primero, lo narra Fabela en el artículo antes señalado, se trata del asesinato del súbdito inglés Willam S. Benton, quien tuvo la osadía de reclamar personalmente y de manera airada a Villa una serie de despojos y arbitrariedades sufridas en sus propiedades a manos de sus tropas. Villa, después de abofetearlo, lo mandó matar. La manera en que se complicó el asunto, la relata así Fabela:

El secretario de Estado William Jennings Bryan se dirigió a mí por conducto del cónsul Simpich, de Nogales, Arizona, en mi carácter de encargado del Despacho de Relaciones Exteriores, diciéndome que el súbdito británico Benton había desaparecido de Chihuahua, que se temía por su vida y que el Gobierno de $\mathrm{Su}$ Majestad le había pedido que interviniera para que se le hiciera pronta y debida justicia.

El Primer Jefe me ordenó:

I. -Que me dirigiera a Villa pidiéndoles informes sobre el caso; y

II. -Que contestara a Bryan previniéndole que, tratándose de un inglés, no aceptaba su representación, la cual debería ser hecha directamente a él por el gobierno de Londres.

Así lo hice. Dirigía a Villa un mensaje — que nunca me perdonó- transcribiéndole la queja y pidiéndole informes. Y después contesté por nota a Mr. Bryan que no aceptaba su intervención en aquel asunto, de acuerdo con las instrucciones del Primer Jefe.

Villa contestó al Primer Jefe que Benton lo había agredido y que habiéndole consignado a un consejo de guerra, éste lo había condenado a muerte y había sido fusilado. Lo que no era cierto, pues Villa lo mandó matar y el consejo condenó a muerte al ya difunto.

La grita en los Estados Unidos y la Gran Bretaña fue tremenda, con sobrada razón. Pero a pesar de todo, Carranza sostuvo su principio oportuno y digno desde su puntos de vista político internacional. Si el Gobierno inglés tenía algo que pedirle, que se dirigiera a su gobierno porque él no aceptaba la práctica seguida por las naciones europeas de considerarnos como tutoreados de la Casa Blanca. 
En el fondo, tales gobiernos consideraban que si ellos no podían intervenir en México, en virtud de la Doctrina Monroe, los que debían representarlos cerca de nosotros, eran los Estados Unidos.

Pero el Primer Jefe no aceptaba y no aceptó en definitiva la Doctrina Monroe; y además quería, y consiguió que triunfara su sostenido criterio político que era el de que los países extranjeros reconocieran, siquiera fuese de facto, la personalidad internacional que tenía derecho a reclamar en nombre de México y de su Gobierno. ${ }^{53}$

El segundo incidente tuvo que ver con la desocupación del puerto de Veracruz, tomado por fuerzas norteamericanas desde el gobierno de Huerta. Cuando ya se había tácitamente acordado la retirada de las tropas invasoras, un agente confidencial se acercó a Fabela para exigir, de parte del gobierno de Washington, que se cumplieran las siguientes condiciones:

$1^{\text {a }}$ Que el Primer Jefe se comprometiera públicamente (...) a no cobrar impuestos a los causantes que ya los habían pagado a las autoridades americanas del puerto; $2^{\text {a }}$ Que no se molestara a las monjas que se iban a embarcar rumbo a Europa; y $3^{\text {a }}$ Que no se castigara a los mexicanos que habían servido a las autoridades extranjeras durante la intervención.

Naturalmente que don Venustiano Carranza jamás pensó realizar aquellos actos, pero no quiso avenirse a las exigencias que pretendía el Gobierno americano, porque eso lo consideraba como una imposición que su decoro y dignidad no le permitían acatar.

Y entonces entramos en un conflicto que vino a terminar práctica y patrióticamente el pueblo veracruzano.

Los causantes de impuestos pagados, las monjas y los empleados que habían servido a las autoridades americanas se dirigieron al gobernador del estado, general Cándido Aguilar, diciéndole que ellos no necesitaban la protección extranjera y que de antemano se atenían a la justificación del Gobierno Constitucionalista.

Entonces, el señor Carranza y el general Aguilar, fundados en aquel nobilísimo y oportuno proceder, dictaron los acuerdos respectivos para finiquitar el conflicto cuya solución se debió al patriotismo de los veracruzanos, quedando así a salvo la dignidad y el honor del Gobierno Constitucionalista. ${ }^{54}$

El sentido crítico de cualquier historiador puede llegar a poner en tela de juicio este relato, al menos parcialmente; sin embargo, sin entrar en materia, vale para resaltar un gesto que continuamente se verá en otras situaciones semejantes en las que Carranza haya tenido que responder ante cualquier asunto que tuviera visos de intromisión norteamericana: su primera reacción

$53 \quad$ Ibid.

54 Isidro Fabela, "Política Internacional de Carranza. La ocupación de Veracruz", Excélsior, 21 de abril de 1953, AH, caja 29 legajo Presidentes de México, s.n.f. 
ha sido de rechazo, sin examinar a fondo las consecuencias, por lo que al menos se puede considerar verosímil.

Sobre la intervención norteamericana en Veracruz también se encuentra un extenso artículo que, de hecho, es la transcripción de todo un capítulo dedicado a México del libro The Senate and de Ligue of the Nations, del senador republicano Henry Cabot Lodge. Apareció como una extensa colaboración en la edición de Excélsior del 21 de noviembre de 1925, y contiene muchas apreciaciones de primera mano que contribuyen a conocer mejor la historia de los hechos. Por ejemplo, afirma Cabot que Wilson "había sido burdamente mal informado sobre la situación por los agentes que tenía en México y abrigaba la idea fija de que el pueblo nos acogería con beneplácito en Veracruz y que nos apoderaríamos de la ciudad sin oposición". ${ }^{55}$ Más adelante señala cómo la situación fue totalmente distinta: "Como consecuencia de esta expedición enviada por Mr. Wilson contra el general Huerta, fueron muertos diecinueve norteamericanos y heridos setenta y uno. Las bajas de los mexicanos fueron ciento veintiséis muertos y ciento noventa y cinco heridos. Fue una guerra". ${ }^{56}$ Prosigue contando cómo al día siguiente del desembarco en Veracruz, fue junto con otros senadores a conferenciar con Wilson y lo hallaron

en un estado de profunda agitación y sumamente alterado, pues jamás hubiera pensado en que hubiera una guerra. Debido a los malos informes que tenía, lo cogió completamente por sorpresa la lucha habida en Veracruz, y estaba hondamente alarmado (...). Naturalmente que jamás debió haber enviado la flota y los marinos a Veracruz, a menos de que hubiese estado preparado no solo para la entrega pacífica de la ciudad, sino también para la resistencia que podía registrarse, y que de hecho se registró (...). Todo lo que parecía deseoso de hacer, habiendo ya ocurrido la lucha, consistía en salir de la dificultad por cualquier medio posible, sin continuar la guerra que él mismo había iniciado. ${ }^{57}$

En otros momentos de su largo escrito, Lodge aborda los sucesos de El Carrizal y la expedición punitiva contra Villa, y concluye que en ambas ocasiones la actitud de Wilson fue errática y titubeante, pues buscaba calmar la agitación pública de los norteamericanos que clamaban venganza en contra de México con sólo una apariencia de escarmiento: "Quería evidentemente hacer lo que fuese necesario para aplacar la agitación pública y evitar la guerra. Estaba anonadado por el temor de perder votos y por el temor de la guerra.

55 Henry Cabot Lodge, "México y Wilson", Excélsior, 21 de noviembre de 1925, pp. 5 y 12, AH, caja 29, legajo Wilson, Huerta, Carranza (1), ff. 30-31.

56 Ibid.

57 Ibid. 
Hallábase en una situación de nerviosidad como cuando lo vi después de la toma de Veracruz, aunque no tan abatido como entonces". 58

\section{DeClaraciones de OBREgón DURANTE EL CONFLICTO RELIGIOSO}

De los problemas habidos entre la Iglesia católica mexicana y el gobierno de Carranza, el Archivo Hunter no contiene información, en cambio, en relación con el conflicto que ya venía arrastrándose desde antes del gobierno de Obregón y que detonó en la presidencia de Plutarco Elías Calles, el material es abundantísimo.

No se pretende ahora reescribir lo que ya ha sido difundido en abundantes libros, muchos de ellos muy cualificados ${ }^{59}$ sino más bien aprovechar el vastísimo material hemerográfico que ofrece el Archivo Hunter para ilustrar algunos hechos menos divulgados. El primero de ellos, en relación con Obregón.

En noviembre de 1926, cuando muchos católicos se habían levantado en armas de manera poco organizada para exigir del gobierno de Calles la derogación de las últimas leyes que habían originado la suspensión del culto por parte de la jerarquía, puesto que algunos obispos consideraban que acatar dichas leyes era tanto como poner la Iglesia bajo las órdenes del gobierno, justo en ese momento candente, el general Obregón -presidente en retiro que todavía no manifestaba sus aspiraciones de reelección- dio a la prensa unas extensas declaraciones en dos partes: una relativa a los momentos que se estaban viviendo; otra, alusiva a un momento álgido de su gobierno, cuando fue expulsado el delegado apostólico Ernesto Filippi, ambas tendientes a hacer recaer en el clero la culpa de todo el conflicto que se vivía.

Comenzaremos por la segunda parte, por ser anterior en el tiempo. Se trata de una larga carta escrita a varios prelados de la Iglesia católica en la que les hacía una invitación a unirse al programa revolucionario, pues él no encontraba ninguna incompatibilidad entre dicho programa y el que sostenía la Iglesia católica en el terreno social:

Los postulados fundamentales del gobierno actual, que cree interpretar fielmente los anhelos populares, pueden considerarse así: Encauzar a todos los hijos de México por el sendero de la Moral, de la Virtud y de la Confraternidad en la más amplia acepción de la palabra, tratando de encontrar dentro de estos postulados un mayor bienestar para la vida terrenal; y sí los programas llegaran a realizarse, sería la conquista máxima de bienestar para todos los habitantes de la Tierra,

$58 \quad$ Ibid.

59 Entre otros muchos, Jean Meyer, La cristiada 1-3; Paolo Valvo, Pio XI e la Cristiada. Fede, guerra e diplomazia in Messico (1926-1929). 
porque la ventura y bienestar quedarían definitivamente conquistados para todos en esta vida y en la otra vida.

La religión católica exige a sus ministros nutrir y orientar el espíritu de sus creyentes. La revolución que acaba de pasar exige al Gobierno de ella emanado, nutrir el estómago, el cerebro y el espíritu de todos y cada uno de los mexicanos, y no hay en este otro aspecto básico de ambos programas nada excluyente y sí una armonía indiscutible.

Yo lamento muy sinceramente que los miembros del alto Clero Católico no hayan sentido la transformación que se está produciendo en el espíritu colectivo, hacia orientaciones modernas, en cuya transformación están perdiendo fuerzas cada día las doctrinas afectivas y abstractas y robusteciéndose las efectivas y sociales, y que a esta vigorosa evolución le estén negando su contingente de cooperación y muchos de ellos estén oponiendo una sistemática obstrucción para su desarrollo, máxime, como antes digo, cuando sus postulados son cristianos en esencia y en su forma y en nada desvirtúan las doctrinas que los miembros de la Iglesia sustentan en su teoría; y si existe alguna falta de armonía, ésta radica principalmente en los métodos distintos que aplican entre sus teorías y sus prácticas. ${ }^{60}$

La carta había sido escrita el 27 de enero de 1923, en respuesta a otra que le habían enviado los obispos el 15 de enero del mismo año protestando por la expulsión del delegado apostólico, Ernesto Filippi, apenas unos días antes. Es comprensible la desazón y el descontento de los obispos por lo que acababa de ocurrir: de una manera inesperada y, sobre todo, violenta, dándole apenas 72 horas para abandonar el país, el representante diplomático de la Santa Sede había sido obligado a retirarse de suelo mexicano por participar en la ceremonia de colocación de la primera piedra de un santuario que se levantaría en el Cerro del Cubilete con lo que, a la vista del gobierno de Obregón, se habían violado gravemente algunas de las leyes vigentes en materia religiosa. La carta del entonces presidente, por más que estaba escrita en un estilo conciliador, fue tomada por los obispos casi como una burla, o como una segunda provocación: ¿cómo podían unirse a un gobierno que les tendía la mano al mismo tiempo que de un modo tan intempestivo y, a su vista, injusto, deportaba perentoriamente al representante del papa? Sobre todo, ¿cómo podía hablar el presidente de que el programa revolucionario y el programa de la Iglesia perseguían los mismos fines?

La respuesta, desafortunadamente, fue todo lo contrario al inicio de un diálogo entre las partes, pues los prelados respondieron a Obregón que el programa revolucionario de corte socialista era opuesto al cristianismo, puesto que "no sabe sino sembrar entre las clases sociales odios y divisiones, hasta

60 “Carta del presidente de la República general Álvaro Obregón al arzobispo de México José Mora y del Río y otros obispos”, 27 de enero de 1923, Excélsior, 7 de noviembre de 1926, AH, caja 14, legajo 6: Mexican Church 1926 (sep-dec), f. 496. 
hace poco desconocidos en México". ${ }^{61} \mathrm{Y}$ en relación con lo que sostenía el presidente sobre lo efectivo del programa de la Revolución y lo teórico del programa de la Iglesia, añadían que "el programa católico tiene la ventaja de ser eminentemente práctico, porque toma al hombre como es, armoniza los intereses espirituales y materiales, temporales y eternos, y cuenta con la autoridad indiscutible de su Divino Fundador". ${ }^{62}$ Con estos argumentos, lejos de que el presidente Obregón entendiera mejor la postura de la Iglesia, conservaría esto como una afrenta, según se vio casi cuatro años después.

Retomando lo publicado en 1926, el alegato principal de las declaraciones de Obregón se centra en la acusación contra el clero de haberse olvidado de las clases populares y de sus demandas, en tanto que los revolucionarios se han ganado, según el mismo Obregón, a las clases proletarias a base de satisfacer sus necesidades. ${ }^{63}$ La misma medida de suspensión del culto público es una disposición que únicamente perjudica a las masas populares,

cuyas condiciones económicas - observa el ex presidente no sin un toque de ironía - no les permiten ni rentar un automóvil para llevar al sacerdote a su casa, ni arreglar un altar para la ministración del sacramento, ni tampoco pagar por este servicio lo que lógicamente debe pagarse cuando se practica a domicilio y mucho menos para preparar el tradicional chocolate para obsequiar a invitados y prelado. ${ }^{64}$

Se queja también de que el clero haya acudido a los católicos norteamericanos para que cooperen con los mexicanos "ya por medio de propaganda periodística, ya contratando ex líderes que van a refugiar su impotencia y su despecho al vecino país", lo cual, augura, no traerá sino funestos resultados para los católicos de aquella nación en la que "tendrán que llevar la peor parte porque significan una completa minoría". ${ }^{65}$

Finalmente, junto con una última acusación al clero y una exhortación a que se sometan al nuevo ordenamiento legal, hace referencia a su carta de 1923 en la que

61 “Carta de José Mora y del Río, arzobispo de México, y tres arzobispos más al general Álvaro Obregón”, 5 de febrero de 1923, AHAM, fondo episcopal: José Mora y del Río, caja 123, expediente 54 .

62 Ibíd.

63 Declaraciones de índole similar había hecho ya el ex presidente unos meses antes, cuando las protestas, zafarranchos y combates apenas iniciaban: "Obregón habla del conflicto religioso. Dice que los altos dignatarios de la Iglesia provocaron las dificultades”, Excélsior, 3 de agosto de 1926, AH, caja 14, legajo 5: Mexican Church 1926, f. 344.

${ }_{64}$ "Expresidente Obregón hace declaraciones sobre la situación económica y política de nuestro país”, Excélsior, 7 de noviembre de 1926, en AH caja 14, legajo 6: Mexican Church 1926 (sep-dec), f. 496.

65 Ibíd. 
el Encargado del Poder Ejecutivo invitaba cordial y francamente a los directores de la Iglesia católica a desarrollar sus actividades limitándose a los cánones de su propio culto y no invadiendo el terreno en que debe actuar la administración pública (...). Que le encomienden a la inteligencia y no a su corazón el estudio de este problema que aún es tiempo de resolver, cuando ellos acepten que han equivocado fundamentalmente su verdadera misión, tratando de llevarla al terreno de la política y al terreno de la violencia y se concreten exclusivamente al ejercicio de su culto aceptando que si es verdad que nuestra revolución les restó mucho poder y mucha riqueza, es tiempo todavía de que puedan salvar la parte de poder y de riquezas que aún les queda. ${ }^{66}$

Aun reconociendo buenas intenciones de Obregón en sus declaraciones, la respuesta del episcopado fue una negativa contundente $y$, a falta de posibilidades de hacerla aparecer en la prensa nacional, fue publicada algunos días más tarde en el diario vaticano. ${ }^{67}$

Sobre el conflicto religioso, es muy escaso el material alusivo a Obregón que se encuentra en el Archivo Hunter, a no ser una caricatura en la que aparecen él y Calles compartiendo la silla presidencial a modo de unos gemelos siameses. Será al período del general Calles e, incluso, a los sucesivos, a quienes Hunter brinde mayor cobertura sobre este tema.

\section{El CONFLICTO RELIGIOSO DURANTE LA PRESIDENCIA DE Calles y el Maximato}

Las cajas 14, 17 y 18 del Archivo Hunter están destinadas a documentos alusivos al conflicto entre la Iglesia y el Estado. Casi siempre recortes de periódicos o revistas pegados en papel cartoncillo. Casi 800 de éstos se encuentran foliados progresivamente y otros tantos sin numerar. Existen algunos años con varios legajos repletos; especialmente 1926, con cuatro.

El 21 de febrero de 1920, a unos meses de que Calles tomara posesión como presidente, ${ }^{68}$ se dio el intento de cisma en el que un grupo de disidentes de la Iglesia católica comenzaron por adueñarse del templo de La Soledad y proclamaron la creación de una iglesia nacional: la Iglesia Católica Apostólica Mexicana (ICAM), de la que quedaba al frente el sacerdote Joaquín Pérez Budar.

$66 \quad$ Ibid.

${ }_{67}$ "En este momento, los católicos no piden otra cosa que la libertad, tal como es reclamada por la verdad y por la justicia, y tal como deriva de los axiomas fundamentales de la misma Constitución, en la que fueron introducidos, por razones sectarias, añadidos contrarios a aquellos axiomas" (L'Osservatore Romano, 10 de diciembre de 1926, p. 1).

$68 \quad$ El 1 de diciembre de 1924. 
Este legajo contiene varios documentos dando cuenta de algunos sucesos alusivos a la recién fundada iglesia nacional: el intento fallido de apoderarse de más templos, la entrega por parte del gobierno de una de las iglesias más emblemáticas en Tapachula a los cismáticos, un telegrama enviado por el patriarca Pérez al obispo de Roma invitándolo a reconocer a la iglesia cismática y darle el trato que se merecería cualquier iglesia apostólica.

Además de esto, cuatro son los temas de que se ocupa: principalmente de la persecución a la Iglesia católica por parte del gobernador Guadalupe Zuno en el estado de Jalisco; ${ }^{69}$ también de la persecución del gobernador Garrido Canabal en el estado de Tabasco; además de ello, la promulgación de una ley que limitaba el número de sacerdotes en el estado de Hidalgo y, al mismo tiempo, exigía que cada uno de éstos fuera autorizado por el gobernador y, finalmente, dos declaraciones de la Santa Sede en relación al problema que se vivía en México: uno del secretario de la delegación apostólica; el otro, del papa Pío XI.

En entrevista realizada a Tito Crespi, quien encabezaba la misión diplomática vaticana en México, éste evitó comentar la reglamentación del número de sacerdotes recién aprobada en Hidalgo explicando que no podía decir "nada a ese respecto porque nosotros no queremos tomar parte en la política oficial, sino que nos limitamos a pedir justicia dentro de las leyes vigentes y a ver si es posible que se respeten los derechos que nos corresponden". ${ }^{70} \mathrm{La}$ otra declaración era del papa, quien durante un consistorio secreto para crear cuatro nuevos cardenales en diciembre de 1925, se refirió dos veces a México con preocupación expresando que "la situación de los asuntos católicos en ese país no es muy consoladora". ${ }^{71}$

De estos asuntos que mayormente documentó Mr. Hunter en su archivo personal referentes al año 1925, quizá vale la pena detenerse en el que abarca la persecución de los católicos en Jalisco, propiciada, según las fuentes periodísticas, por el gobernador Zuno y sus seguidores. No es que este hecho sea del todo desconocido, sino que quizá no se le haya dado hasta ahora la preeminencia que le corresponde. Con frecuencia se menciona la fundación de la ICAM como un antecedente que puso en alerta a los católicos y los llevó a organizarse de cara a lo que había de venir durante la gestión de Calles; también se da importancia a las medidas estridentes del gobernador Garrido

69 Da cuenta, por ejemplo, del asesinato de un sacerdote a manos de agraristas, de desalojo de los dos seminarios de Guadalajara, de la represión a manifestaciones pacíficas de protesta, de la búsqueda que se realizaba para aprisionar al obispo Orozco y Jiménez...

70 "La situación de la Iglesia ya va mejorando", Excélsior, 14 de noviembre de 1925, AH, caja 14, legajo 1: Mexican Church 1925, f. 42.

71 "Su Santidad habla sobre nuestro país", Excélsior, 15 de diciembre de 1925, AH, caja 14, legajo 1: Mexican Church 1925, f. 47. 
Canabal en el estado de Tabasco que llevaron a que en ningún sitio del estado pudiera celebrarse la Misa o administrarse cualquier otro sacramento. No obstante, la ICAM no tuvo mayor éxito y en unos meses se desdibujó hasta casi desaparecer y Tabasco, a pesar de la crudeza de la persecución, era un estado con pocos habitantes, pocos sacerdotes y poca tradición religiosa.

Por ello, las agresiones a los católicos en Jalisco - uno de los estados del país más poblados y con mayor fervor religioso-, si bien intermitentes, sin duda coadyuvaron a la percepción de un verdadero estado de guerra contra la religión católica que puso sobre aviso a los católicos para, unos meses después, levantarse en armas contra las medidas restrictivas de la administración de Calles. Esto, que parcialmente ha sido traspapelado en la historia por otros eventos aparentemente más decisivos, sin embargo, fue señalado como un foco rojo por los diarios del momento.

Así, en la primera plana del 28 de julio de 1925, el Excélsior anunciaba que los alumnos del seminario de Guadalajara habían sido desalojados a tiros y culatazos. Hablaba de una gran consternación local y mencionaba que, entre los seminaristas heridos, "uno está de tal manera grave que se cree que morirá de un momento a otro". ${ }^{72} \mathrm{Al}$ día siguiente, el mismo diario informaba de una multitudinaria manifestación de católicos que protestaban por el hecho que fue reprimida por la policía con ayuda de los bomberos. También mencionaba que varios connotados católicos habían sido encarcelados y que se sabía que el arzobispo Orozco y Jiménez era buscado para reducirlo a prisión. En tanto que el gobernador Zuno respondía "que mandó clausurar los Seminarios que existían en Guadalajara porque se estaba cometiendo una flagrante violación de las Leyes de Reforma y de los artículos tercero y quinto de la Constitución". ${ }^{73}$

También los periódicos del bajío daban cuenta de lo que llamaron "persecución zunista". De esta forma el periódico Correo del Centro de León, Guanajuato, reportaba con grandes titulares la siguiente noticia: "Asesinan Salvajemente a un Anciano Sacerdote Católico algunos agraristas Zunistas. La persecución religiosa desatada por Zuno en el Estado de Jalisco comienza a dar sangrientos resultados". ${ }^{74} \mathrm{El}$ sacerdote asesinado se llamaba J. Crescencio Aguilar, en un punto cercano a la estación del tren El Castillo.

El año 1926 está integrado por cuatro gruesos legajos con material alusivo al conflicto religioso que se agudizaría a partir de ese año. Aunque se puede

72 “Arrojan a culatazos a alumnos del Seminario", Excélsior, 28 de julio de 1925, p. 1, AH, caja 14, legajo 1: Mexican Church 1925, f. 15.

73 "La gran manifestación de católicos que acudían a Palacio fue disuelta por la Policía y por los Bomberos que acudieron violentamente", Excélsior, 29 de julio de 1925, p. 1, AH, caja 14, legajo 1: Mexican Church 1925, f. 16.

74 "Asesinan salvajemente a un anciano sacerdote católico agraristas zunistas", Correo del Centro, 18 de septiembre de 1925, p. 1, AH, caja 14, legajo 1: Mexican Church 1925, f. 27. 
reconstruir éste a partir de los recortes coleccionados por Hunter, no se ve necesario, habiendo obras que lo hacen de una manera más extensa y con apoyo en gran número de fuentes y no sólo de la prensa. ${ }^{75}$ Para los fines de este trabajo se ha visto más útil presentar aquellos datos que manejaba la prensa y que no han sido quizá tan comentados, como el hecho de que a principios de marzo, a causa de la feroz represión que comenzaba a darse contra algunos sectores del catolicismo, el senador norteamericano por Nueva York, John Boylan, pidió que se quitara a México el reconocimiento de los Estados Unidos.

Sostuvo que era imposible que los Estados Unidos siguieran tratando con el Gobierno mexicano, debido a que la Constitución mexicana "hace a un lado el Derecho internacional que en general prevalece entre la familia de las naciones". ${ }^{76}$

El diario calificaba de "peregrina" la petición del senador neoyorquino, quien en meses sucesivos seguiría pugnando porque su país tomara represalias contra el gobierno mexicano por su política antirreligiosa.

Las notas conservadas en el archivo nos permiten dar seguimiento puntual a los acontecimientos que ensombrecieron la historia del país por casi tres años. En los cuatro legajos correspondientes a 1926 se puede reconstruir lo que dijo la prensa sobre las declaraciones de febrero del arzobispo Mora y del Río, el endurecimiento de las leyes en los estados, cierre de escuelas y de instituciones de beneficencia, expulsión de los sacerdotes extranjeros, consignación ante las autoridades de los obispos Mora y Manríquez, promulgación de la llamada Ley Calles, boicot y protestas, suspensión del culto público y, aquí nos detenemos para mencionar un hecho quizá menos conocido, acuartelamiento de los soldados desde unos día antes de que la ley impugnada por los católicos entrara en vigor. Una medida preventiva que permitía avizorar los inminentes zafarranchos de protesta. Así lo informaban los periódicos en su edición del 29 de julio:

Se ha resuelto por parte de las autoridades militares que a partir del sábado próximo, 31 de julio, hasta nueva orden, las fuerzas militares de toda la República permanezcan rigurosamente acuarteladas (...). Estarán a la expectativa, pero solamente intervendrán cuando sea pedido su auxilio por las autoridades locales, y siempre que de otro modo no se haya conseguido reducir a los que pretendan oponerse a las disposiciones del Gobierno. ${ }^{77}$

75 Dos clásicos para el conocimiento de este asunto son Jean Meyer, La Cristiada 1-3, y Paolo Valvo, Pio XI e la Cristiada. Fede, guerra e diplomazia in Messico 1926-1929.

76 "Una peregrina petición del Senador Boylan", Excélsior, 6 de marzo de 1926, AH, caja 14, legajo 2: Mexican Church 1926, f. 127.

77 Las tropas federales se acuartelarán en el país", Excélsior, 29 de julio de 1926, AH, caja 14 legajo 4: Mexican Church 1926, f. 319. 
En los días sucesivos, las notas de prensa estuvieron cargadas de optimismo y esperanza de una solución rápida, sobre todo cuando se conoció la entrevista concedida por Calles a un par de obispos. Excélsior mencionaba en su editorial que

no estamos lejos de una resolución decorosa para ambas partes; así lo anuncia el Comité Episcopal en términos claros y precisos. Y al manifestarlo quienes más autorizados están para dar tan grata nueva, contribuyen poderosamente a mejorar la triste situación porque atraviesa el país, situación de incertidumbre en las conciencias, de tirantez económica en los negocios, de malestar en todos los órdenes de la vida. ${ }^{78}$

La flama del optimismo se desvaneció muy pronto y, a partir de ahí, el tono de las noticias tornó a ser preocupante: ataques mutuos, polarización, diputados que rechazan con abrumadora mayoría las peticiones de los católicos, estallido de la violencia en algunos estados del país, acusaciones de un lado y de otro, guerra contra los rebeldes y, más tarde, Obregón anuncia que buscará la presidencia, reforma de la Constitución para que pueda reelegirse y ahora para un período de seis años, fusilamiento de sus principales oponentes, triunfo avasallador en las urnas y... asesinato del presidente electo, general Álvaro Obregón, a manos de un joven católico. Sobre esto, se encuentra un extenso relato de José de León Toral en el que él mismo narra las motivaciones de su crimen y el modo en que lo llevó a cabo. ${ }^{79}$

La cantidad de recortes sobre el conflicto disminuyen a partir de la llegada al poder del licenciado Portes Gil, en diciembre de 1928, pero no faltan noticias del atentado dinamitero contra el tren en que viajaba, durante el siguiente mes de febrero, ni tampoco los presagios de un arreglo entre la jerarquía eclesiástica y el gobierno que permitirían reanudar el culto público en junio de 1929, la reapertura de los templos y los primeros enfrentamientos entre la jerarquía y una parte de la feligresía católica inconforme porque no habían sido derogadas las leyes que habían originado el conflicto. También interesantes fueron las declaraciones del arzobispo Leopoldo Ruiz y Flores, ahora convertido en delegado apostólico, quien afirmó en octubre de 1929 que los católicos, como tales, no estaban apoyando la campaña de Vasconcelos o algún otro candidato a la presidencia y que el episcopado y el clero debían mantenerse en una posición que los colocaba fuera de todo partido político y de toda política de partido.

78 "Presagios optimistas", Excélsior, 23 de agosto de 1926, AH, caja 14, legajo 5: Mexican Church 1926 (aug), f. 421.

79 “León Toral narra su crimen”, El Universal, 3 de noviembre de 1928, AH, caja 14, legajo 8: Mexican Church 1928, f. 661. 
Ya en 1930, las noticias que conservó Hunter en su archivo fueron pocas, y relacionados con las protestas que, mediante la publicación de panfletos, algunos católicos seguían haciendo en contra de los obispos que habían acordado los arreglos.

En 1931, después de algunos meses de tregua, en algunos estados como Veracruz, se reiniciaron las provocaciones contra la Iglesia católica mediante actos de represión y una ley que permitía únicamente la existencia de un ministro de culto por cada 160000 habitantes. En otros, como Jalisco, se había intensificado la persecución y eliminación de aquellos que habían participado en la resistencia armada de los años 1926-1929. Sobre esto, se encuentran varias noticias tanto de la prensa nacional como de la norteamericana. Una que cabe comentar es la que narra cómo un católico que había participado en la contienda cristera y ahora se dedicaba a colaborar con un asilo de huérfanos de la guerra, fue secuestrado y desaparecido por militares y, a pesar de que el juez primero de distrito interpuso un amparo, las fuerzas públicas negaron haberlo detenido. El juez, en un acto valiente y desesperado, escribió al presidente Pascual Ortiz Rubio y dio a conocer a la prensa tanto el amparo como el ocurso al primer magistrado, en el que explicaba lo siguiente:

En amparo promovido por Julio R. Castañeda contra actos del general Juan B. Izaguirre, Jefe de la Guarnición de esta plaza, ordene la suspensión para que sea respetada la vida del quejoso. Dicha autoridad niega haberlo detenido, pero hay pruebas de lo contrario y de que su vida está seriamente amenazada. Por respeto a nuestras leyes exhorto a usted para que sea obedecido el mandato judicial. ${ }^{80}$

El cadáver de Castañeda fue encontrado a las afueras de Guadalajara.

Como a la vista de muchos el gobierno no estaba cumpliendo lo pactado, comenzaron nuevamente los preparativos para un eventual levantamiento armado por parte de los católicos. Los obispos de las diferentes diócesis, junto con el delegado apostólico, salieron al paso de esta posibilidad y exhortaron al pueblo católico a no levantarse en armas. Así, por ejemplo, el arzobispo de Guadalajara, Orozco y Jiménez, quien se vio en la obligación de escribir una carta pastoral que se leyera en todas las parroquias de su diócesis en la que advertía:

No es raro encontrar individuos que, queriendo sorprender la buena fe de los fieles, se hacen aparecer como enviados por mí o por cualquier otro de los señores Obispos, so pretexto de que dichos levantamientos se harán ostentando bandera religiosa; estad prevenidos y no deis crédito a quienes con tanta facilidad 
calumnian, sin prever las graves consecuencias que de tal cosa se desprenden, o bien con la marcada intención de desacreditar a la autoridad eclesiástica.

Además, claramente nos lo ha dicho el Sumo Pontífice, y todos los cristianos como obedientes hijos debemos estar a sus mandatos, que cuando queramos alcanzar este o aquel bien para la Santa Iglesia, no pretendamos obtenerlo por medios violentos. ${ }^{81}$

A partir de este momento nos encontraremos exhortaciones parecidas por parte del episcopado en la línea de atajar posibles levantamientos armados de católicos, que seguían considerando estos, una vía lícita para obtener ciertas reivindicaciones, una vez que se habían agotado todos los medios pacíficos y legales.

Otros dos sucesos son recogidos por los dos legajos del archivo Hunter relativos al año 1931: la muerte del patriarca Pérez y la celebración del 400 aniversario de las apariciones de la Virgen de Guadalupe.

En relación con el primer evento, las noticias que se recogen resultan un tanto contradictorias, pues mientras que en algunas notas se acentúa que era masón del rito metropolitano y que los masones, junto con los cismáticos, se encargaron de organizar su sepelio, en otras, lo que se subraya es que murió arrepentido de haber provocado el cisma, que solicitó en sus últimos momentos la asistencia de un cura católico y que, movido por éste, firmó un acta de retractación, misma que fue difundida por algunos de los diarios.

El año 1931 se cerró con un acontecimiento que volvió a mover las aguas, si es que alguna vez estuvieron quietas, del conflicto religioso: la celebración de los 400 años de las apariciones guadalupanas con una magna fiesta que duró varios días y en la que participaron la mayoría de los obispos del momento y una gran cantidad de fieles venidos del interior. Se juzga que en un solo día fueron cerca de 50000 los que participaron. A alguno de los eventos festivos acudió una buena parte del cuerpo diplomático acreditado en México, así como algunos ministros del gobierno de Pascual Ortiz Rubio, como Luis Montes de Oca y Manuel C. Téllez. Todo esto llevó a que el ala más radical del congreso reaccionara con una cólera desproporcionada y consiguiera la remoción de algunos funcionarios pero, sobre todo, la continuación de un estado de persecución que parecía ya superado. Una de las medidas que se tomaron fue la de permitir únicamente un ministro de culto por cada 50000 habitantes y especificar en la misma ley que dicho sacerdote sólo podría desempeñar sus funciones en el templo para el que hubiera sido autorizado.

Los discursos en las cámaras contra aquellos que habían apoyado de algún modo los festejos guadalupanos se prolongaron por casi tres semanas.

81 "Carta pastoral del Arzobispo de Guadalajara del 31 de agosto", La Prensa, 6 de septiembre de 1931, p. 3, AH, caja 17, legajo Mexican Church 1931, f. 8. 
No faltaron acusaciones incluso en contra del general Calles, como ésta, que desmintió Gonzalo N. Santos: "se rumora que el general Calles dio diez mil pesos para las obras de la Villa de Guadalupe y fue él quien arregló que entrara el órgano libre de derechos al país, pero no es tal (...), puesto que el sabría morir en los brazos de la Revolución". ${ }^{82}$

Efectivamente, no sólo no intervino apoyando, sino que, según narra uno de los hombres de confianza de Calles, el ingeniero Puig y Causaranc, su disgusto fue mayúsculo y convocó a una reunión para que los ministros implicados le dieran explicaciones de lo que había pasado. ${ }^{83}$ La reprimenda fue destemplada y humillante para los involucrados.

Entre los años 1932 y 1934 disminuyeron un tanto los textos recogidos por Hunter y los recortes que se conservan son mayoritariamente de tres revistas de extracción católica: La Época, La Palabra y Criterio. En éstas abunda el material sobre las medidas restrictivas emprendidas contra la Iglesia católica en el estado de Veracruz y otras notas de carácter nacional como el cierre continuo de templos, incluso incendios y saqueos, o protestas para evitar que algunos emblemáticos, como el santuario de Nuestra Señora de la Salud en Colima, fuera clausurado y dedicado a otros usos.

Del año 1934 se encuentra material para documentar el recrudecimiento de la persecución religiosa en Sonora; las protestas del arzobispo de México, Pascual Díaz Barreto, contra las iniciativas de introducir primero la educación sexual y, después, la educación socialista; reportes de estados, como Querétaro, con todos los templos cerrados. También otras medidas totalmente anecdóticas, pero que no dejaban de irritar al pueblo católico, como la prohibición de visitar los panteones el día de muertos de 1934 en el estado de Sinaloa. Y, en aproximadamente la mitad de los estados, una reducción desproporcionada del número de sacerdotes autorizados para ejercer su ministerio.

Dentro de todo este entramado, los católicos inconformes con los arreglos no cejaban de hostilizar al arzobispo Pascual Díaz. Fue memorable la zancadilla que le metieron cuando en la revista Criterio publicaron un artículo firmado por él en el que atacaba algunos preceptos constitucionales, situación que ya había traído, en la época de Mora y del Río, consecuencias desastrosas. El prelado inmediatamente negó la autoría del artículo, pero los editores de Criterio mostraron que sí lo había escrito, pero en 1924 y para una revista católica de poca circulación. A través de un comunicado en La Palabra, los directivos de la Liga Nacional Defensora de la Libertad negaron que Criterio

82 “Altos funcionarios públicos atacados virulentamente por los festejos religiosos", La Prensa, 15 de diciembre de 1931, p. 3, AH, caja 17, legajo Mexican Church 1931, f. 50.

83 Puig, De Obregón a Cárdenas, pp. 122-125. Véase también Alessio, Historia política de la Revolución, pp. 342-345. 
fuera un órgano suyo. Su deslinde fortuito permitió ver que algo tendrían que ver.

De los años posteriores a 1934, Mr. Hunter ya no se abocó a la recolección de periódicos que trataran el tema de las relaciones entre la Iglesia y el Estado en México. Tal vez habían cambiado sus preocupaciones o, más probablemente, se vivían tiempos de distensión y los problemas que en otro momento habían ocupado muchas planas de los diarios nacionales, habían comenzado a caminar por vías de solución.

\section{LÁZARo CÁRDENAS Y LA EXPROPIACIÓN PETROLERA}

Un tema que ocupó la atención de Hunter y del que se halla abundante material hemerográfico en su archivo, fue el de la expropiación petrolera y, más extensamente, el conflicto entre las compañías petroleras y el gobierno mexicano durante los meses que antecedieron y siguieron a dicha expropiación.

El enfrentamiento entre los trabajadores sindicalizados y las compañías petroleras no era algo nuevo y se había venido agudizando en los meses anteriores a la nacionalización. El Sindicato de Trabajadores Petroleros de la República Mexicana, creado en 1936, había conseguido unificar los esfuerzos de los trabajadores de las cerca de 20 compañías petroleras que laboraban en el país y, además de un contrato colectivo de trabajo, había exigido que se elevaran las prestaciones de sus agremiados en un monto total de noventa millones de pesos anuales. Las empresas ofrecieron únicamente catorce. Los trabajadores acudieron a la Junta Federal de Conciliación y Arbitraje que, después de un estudio, estableció que las empresas podían pagar veintiséis millones. Como se ve, el monto estipulado era mucho menor que el solicitado por el sindicato; sin embargo, las empresas se negaron, acudieron a la Suprema Corte de Justicia que el 1 de marzo de 1938, confirmó el laudo de la Junta de Conciliación.

Con esta resolución última e inapelable parecía que el problema había terminado, pero las empresas petroleras persistieron en su negativa. Ante esa actitud se comenzaron a caldear los ánimos y, en la Cámara de diputados y en la prensa, el ala radical del Partido Nacional Revolucionario demandó que se expropiara a las compañías que se negaran a acatar el laudo de la Suprema Corte y acusó a todas ellas de sediciosas.

A través de la prensa las compañías aclararon que "han recurrido a los recursos legales para la defensa legítima de sus intereses, pero ninguno de sus actos puede calificarse de subversivo ni de contrario al orden, que es la condición indispensable del funcionamiento eficaz de toda empresa, grande o 
pequeña". ${ }^{84}$ No obstante, no cedían en lo concerniente a pagar lo que la Junta de Conciliación había establecido y la Suprema Corte había corroborado.

Con ánimo de mediar, el presidente Cárdenas aceptó recibir a los abogados de las firmas petroleras. Silva Herzog relata que la osadía y la prepotencia de éstos obligaron al presidente a retirarse de la reunión. ${ }^{85}$ La suerte estaba echada.

El 18 de marzo, los diarios informaban todavía del desacato de las compañías petroleras, que habían planteado como una última oferta al sindicato otorgarles 22 millones de pesos, en vez de los 26 que había fijado la Junta de Conciliación y avalado la Suprema Corte. La diferencia era tan pequeña que, más que un esfuerzo para llegar a un entendimiento parecía que querían salirse con la suya y no obedecer las instancias judiciales del país.

Una noticia del Excélsior reproducía las declaraciones de un líder obrero norteamericano, John Lewis, que invitaba a las empresas petroleras a acatar el fallo:

La convicción de la Comisión de Organización Industrial es que tanto los trabajadores como los patrones deben acatar los fallos de las autoridades legalmente constituidas en las naciones demócratas (...). No veo el motivo de que los trabajadores y empleados de México no acaten este principio, cuando ambas partes han sometido su caso a las autoridades del país. ${ }^{86}$

Ese día por la tarde se dio a conocer el decreto de expropiación que, al día siguiente, reproducirían todos los diarios del país, en el que se decía:

Considerando que es del dominio público que las empresas que operan en el país y que fueron condenadas a imponer nuevas condiciones de trabajo por el grupo número 7 de la Junta de Conciliación y Arbitraje el 18 de diciembre último expresaron su negativa a aceptar el laudo pronunciado, no obstante haber sido reconocida su constitucionalidad por ejecutoria de la Suprema Corte de Justicia de la Nación (...) Se declaran expropiados por causa de utilidad pública y a favor de la Nación, la maquinaria, instalaciones, edificios, oleoductos, refinarías, tanques, estaciones de almacenamiento, vías de comunicación, carros-tanque, estaciones de distribución, y todos los demás bienes muebles e inmuebles... ${ }^{87}$

"Declaraciones de las compañías petroleras", Excélsior, 9 de marzo de 1938, AH, caja 75, legajo Cárdenas, Ávila Camacho, Alemán, Ruiz Cortines, s.n.f.

85 Silva, Trayectoria ideológica de la Revolución Mexicana, p. 147.

86 "John Lewis Declaró en Washington que los Petroleros Deben Acatar el Fallo de la Autoridad Legal”, Excélsior, 18 de marzo de 1938, AH, legajo Cárdenas, Ávila Camacho, Alemán, Ruiz Cortines, s.n.f.

87 "Texto del Decreto de Expropiación firmado hoy por el Ejecutivo. La Secretaría de la Economía Nacional, con intervención de la de Hacienda, tomará posesión de los bienes", 
Los días y semanas sucesivas las noticias del periódico giraban en torno a la expropiación e informaban cómo las empresas petroleras preparaban una campaña legal y diplomática para revertirla y, para sorpresa de muchos, cómo el gobierno norteamericano no protestó ni amenazó a México con represalias. Lo mismo que la prensa. Así lo hicieron ver los periódicos locales: "Varios de los periódicos de Nueva York comentaron hoy la expropiación de bienes pertenecientes a las compañías petroleras en México, pero sus observaciones se caracterizaron por un tono de moderación" ${ }^{88}$ Esta situación no acostumbrada desconcertó incluso a los mismos redactores norteamericanos, según lo confesaba el corresponsal del Herald Tribune: "No puede uno menos que sorprenderse de la relativa calma con que el público ha recibido la noticia de este suceso que hace diez o quince años habría encendido las primeras páginas de los periódicos y tal vez ocasionado una movilización de tropas hacia la frontera". ${ }^{89} \mathrm{Y}$ ¿qué era lo que estaba pasando? El mismo reportero aventuraba tres posibilidades, aunque no habría que descartar una combinación de todas ellas: "Probablemente es un signo del cambio de los tiempos; probablemente refleja las preocupaciones contemporáneas en otros conflictos, o probablemente indica un instinto popular de que el problema es, más de lo que se cree, susceptible de un racional arreglo. Y puede decirse que la calma jamás ha estorbado la marcha hacia un arreglo". ${ }^{90}$

Otro signo del cambio de los tiempos fue la actitud de los fieles católicos y de su jerarquía, que desde el primer momento apoyaron al gobierno en la donación y recolección de fondos para el pago de la deuda contraída con la expropiación de sus bienes a las empresas petroleras. El obispo coadjutor de Morelia, Luis M. Altamirano, a nombre de todo el episcopado, declaraba lo siguiente:

Aunque no ha sido necesaria ninguna exhortación para que los católicos mexicanos contribuyan generosamente con el Gobierno de la República a pagar la deuda contraída con motivo de la nacionalización de las empresas petroleras; juzgando que es oportuno expresar la actitud uniforme y reflexiva del Episcopado Mexicano en asunto tan importante, el Comité Episcopal, en nombre de dicho Episcopado, declara que no solamente pueden los católicos contribuir para el fin expresado en la forma que les parezca más oportuna, sino que esta contribución será un testimonio elocuente de que es un estímulo para cumplir los deberes

Excélsior, 19 de marzo de 1938, AH, legajo Cárdenas, Ávila Camacho, Alemán, Ruiz Cortines, s.n.f.

88 "Desusada moderación de la prensa de Estados Unidos sobre el asunto petrolero", Excélsior, 23 de marzo de 1938, AH, legajo Cárdenas, Ávila Camacho, Ruiz Cortines, s.n.f.

$89 \quad$ Ibid.

$90 \quad$ Ibid. 
ciudadanos de la doctrina católica, que da una sólida base espiritual al verdadero patriotismo. ${ }^{91}$

Esta actitud de los católicos fue subrayada incluso por autores habitualmente críticos de la Iglesia católica. Así, por ejemplo, lo hace Silva Herzog: "Hay algo que es justo confesar: la Iglesia católica estuvo con el gobierno en esa ocasión; aceptó que hubiera colectas en las iglesias para pagar la deuda petrolera". ${ }^{92}$

\section{DONDE LA HISTORIA SE AGOTA: OTROS TEMAS RECOGIDOS POR HUNTER EN SUS RECORTES DE PRENSA}

A partir de la presidencia de Lázaro Cárdenas, la preocupación sostenida de Hunter sobre las relaciones entre la Iglesia y el Estado se diluye y, más que diluirse, se diversifica. Ahora son otros temas los que le interesan. De su preocupación anterior sólo recogerá algunas noticias alusivas a una progresiva conversión de Calles al catolicismo. ${ }^{93}$ Ahora se centrará en otros temas: sociedades secretas, la supuesta amenaza del comunismo e, incluso, frivolidades y chismes de las principales familias de políticos, incluidos escándalos conyugales.

En el legajo "Secret Societies 1937-1949”, Hunter recoge una gran cantidad de artículos y notas periodísticas sobre la masonería, ataques de ésta hacia la Iglesia católica, reuniones de masones, logros filantrópicos y abundante información sobre los shriners.

Del legajo "Communism 1936-1947", cabe subrayar el miedo que se advierte ante el avance comunista en los documentos que contiene. Puede servir de ejemplo el artículo de Antonio Díaz Soto y Gama titulado "Si los comunistoides triunfasen", en el que el controvertido revolucionario denuncia el sinfín de catástrofes que llegarían a México si triunfase el comunismo:

"Obligación de los católicos: el Comité Episcopal los excita a cooperar pro Deuda Petrolera", Últimas Noticias, 2 de mayo de 1938, AH, legajo Cárdenas, Ávila Camacho, Ruiz Cortines, s.n.f.

92 Silva, Trayectoria ideológica, p. 149.

$93 \mathrm{AH}$, caja 27, legajo Calles, con folios sin numerar, contiene abundante material de los meses previos al destierro de Calles y de su gradual acercamiento al catolicismo: "El general Calles se despide agradecido de las monjas del hospital que lo atendieron", La Prensa, 6 de febrero de 1935; "Catholic Calles?", America, 29 de abril de 1944; Guillermo Zárraga, "Calles reconoció que la Lucha Religiosa fue su Peor Yerro", Excélsior, 20 de octubre de 1945; Eduardo Correa Jr. "Un sacerdote logró conmover al General Calles hasta las Lágrimas", Excélsior, 20 de octubre de 1945. 
Unos cuantos años de dominación por parte de los comunistoides significarían la ruina completa de México y la pérdida de la escasas libertades que aún subsisten: producirían el derrumbamiento inevitable de la economía pública y privada, la miseria más cruel, la ruptura con el mundo civilizado, la fuga definitiva de los capitales, el hundimiento de los negocios, la muerte por inanición y por hambre (...). Y algo más pavoroso: el ateísmo y el materialismo se apoderarían de las nuevas generaciones. Los padres dejarían de ser padres, pues tendrían que dejar en manos de los profesores de la secta triunfante el cuidado de formar -o deformar-el alma de sus hijos. ${ }^{94}$

Otros artículos de este legajo permiten ver que, más que una preocupación, en algunos estratos de la sociedad como al que pertenecía Hunter, existía un verdadero pavor ante una eventual llegada al poder de los comunistas. En general los recortes de prensa que se conservan tienden a mostrar una falta de escrúpulos por parte de los comunistas en la consecución de sus objetivos. Un ejemplo de éstos es reportaje en el que un ex líder comunista de los Estados Unidos, Louis F. Budenz, narra cómo se tramó en el extranjero el asesinato de León Trotsky. ${ }^{95}$

\section{CONSIDERACIONES FINALES}

Si bien, a primera vista, un archivo constituido únicamente por fragmentos de periódicos elegidos al azar por un empleado de alto nivel de una empresa tabacalera extranjera no necesariamente tendría mayor interés para los investigadores; sin embargo, cuando ha habido una labor perseverante de organizar por temas y durante años esos textos, vale la pena al menos hurgar en ellos y, como se puede ver a lo largo del breve recorrido que hemos hecho en este trabajo, se encontrarán siempre noticias y datos que apoyen líneas de investigación ya existentes o, incluso, lleven a abrir otras nuevas. ${ }^{96}$

Como se hacía ver al inicio, el Archivo Hunter cuenta también con una sección de libros y revistas que en este artículo no se mencionan, pero que también pueden atraer el interés de los investigadores en determinadas áreas. ${ }^{97}$

94 Antonio Díaz Soto y Gama, "Si los comunistoides triunfasen", El Universal, 22 de mayo de 1940, AH, caja 58, legajo Communism, s.n.f.

95 Gualterio R. Douglas, "Budenz relata cómo se preparó el asesinato de León Trotsky", Excélsior, 8 de mayo de 1947, pp. 1 y 6, AH, caja 58, legajo Communism, s.n.f.

96 Para darle una cierta unidad a esta narración, no se consideraron otros temas que también fueron abundantemente documentados por Hunter: "Spanish Colonies", "Spain 1936-1938", "Hispanidad" y otros cinco legajos con el título "Spain" seguidos por años sucesivos. También tres legajos con sobre "Braceros" y varios legajos únicos con los siguientes temas: "World War 1941-1942", "Ambassadors", "Canada", "Switzerland", "Scandinavia", "Low Countries-Belgium-Holland”, "Ireland” y algunos más.

${ }_{97}$ Las revistas que se encuentran en número considerable son sobre todo Aux carrefours de l'histoire (1960-1961), Boletín de Información de la Embajada de la URSS (1957-1969), 
En cuanto a los textos elegidos para ilustrar el marco histórico que abarca la sección que revisamos, debemos admitir que son insuficientes para dar una idea completa de los acontecimientos y, más aún, para realizar un estudio crítico de la época que retratan; sin embargo, aun con estas carencias, no impiden que se reconstruyan alrededor de veinticinco años de historia del México revolucionario y posrevolucionario con la frescura que se leen en la prensa las noticias de todos los días.

\section{Bibliografía}

Alessio Robles, Miguel, Historia politica de la Revolución, México, Ediciones Botas, 1946.

Harrison, John P., "Henry Lane Wilson, el trágico de la Decena", Historia Mexicana, vol. 6, núm. 3, enero-marzo, 1957, pp. 374-405.

Márquez Sterling, Manuel, Los últimos días del Presidente Madero (Mi gestión diplomática en México), La Habana, El Siglo XX, 1917.

Meyer, Jean, La Cristiada 1-3, México, Siglo XXI, 1973.

Puig Casauranc, José Manuel, De Obregón a Cárdenas. Galatea rebelde a varios pigmaliones, tomo II, México, Senado de la República, 2004.

Silva Herzog, Jesús, Trayectoria ideológica de la Revolución Mexicana, México, El Colegio Nacional-Fondo de Cultura Económica, 1994.

Smith, Michael M., "Diplomacia en las sombras: agentes secretos carrancistas", Provincias Internas 7/8, 2002-2003, pp. 1-16.

Ulloa, Bertha, Historia de la Revolución mexicana 4, Periodo 1914-1917, La Revolución escondida, México, El Colegio de México, 1979.

DOI: https://doi.org/10.2307/j.ctv233n0t

Valvo, Paolo, Pio XI e la Cristiada. Fede, guerra e diplomazia in Messico (1926-1929), Brescia, Morcelliana, 2016.

\section{Archivos}

Archivo Thomas S. Hunter (AH).

Archivo Histórico de la Arquidiócesis de México (AHAM).

Boletín de la Sociedad Chihuahuense de Estudios Históricos (1942-1962), Columbia Knights of Columbus Magazine (1964-1967), Divulgación Histórica (1940-1943), Lectura, libros e ideas (1937-1942), National Review (1963-1970), Preliminary studies of the Texas Catholic Historical Society (1930-1936) y Revista de la Universidad de México (1959). 